\title{
Article \\ Acoustic Emission Wave Velocity Measurement of Asphalt Mixture by Arbitrary Wave Method
}

\author{
Jianfeng Li ${ }^{1} \mathbb{D}$, Huifang Liu ${ }^{1}$, Wentao Wang ${ }^{1}$, Kang Zhao ${ }^{1}$, Zhoujing Ye ${ }^{1} \mathbb{D}$ and Linbing Wang ${ }^{2, *}$ \\ 1 National Center for Materials Service Safety, University of Science and Technology Beijing (USTB), \\ Beijing 100083, China; jianfengli@xs.ustb.edu.cn (J.L.); b20200488@xs.ustb.edu.cn (H.L.); \\ wentaowang@ustb.edu.cn (W.W.); b20180446@xs.ustb.edu.cn (K.Z.); yezhoujing@ustb.edu.cn (Z.Y.) \\ 2 Joint USTB Virginia Tech Lab on Multifunctional Materials, Department Civil \& Environmental Engineering, \\ USTB, Virginia Tech, Blacksburg, VA 24061, USA \\ * Correspondence: wangl@vt.edu
}

check for updates

Citation: Li, J.; Liu, H.; Wang, W.; Zhao, K.; Ye, Z.; Wang, L. Acoustic Emission Wave Velocity Measurement of Asphalt Mixture by Arbitrary Wave Method. Appl. Sci. 2021, 11, 8505. https://doi.org/ 10.3390/app11188505

Academic Editor: Luís Picado Santos

Received: 26 August 2021

Accepted: 10 September 2021

Published: 13 September 2021

Publisher's Note: MDPI stays neutral with regard to jurisdictional claims in published maps and institutional affiliations.

Copyright: (c) 2021 by the authors. Licensee MDPI, Basel, Switzerland. This article is an open access article distributed under the terms and conditions of the Creative Commons Attribution (CC BY) license (https:// creativecommons.org/licenses/by/ $4.0 /)$.
Featured Application: A new method for measuring the acoustic emission wave velocity of an asphalt mixture is proposed in this paper.

Abstract: The wave velocity of acoustic emission (AE) can reflect the properties of materials, the types of AE sources and the propagation characteristics of AE in materials. At the same time, the wave velocity of $\mathrm{AE}$ is also an important parameter in source location calculation by the time-difference method. In this paper, a new AE wave velocity measurement method, the arbitrary wave (AW) method, is proposed and designed to measure the AE wave velocity of an asphalt mixture. This method is compared with the pencil lead break (PLB) method and the automatic sensor test (AST) method. Through comparison and analysis, as a new wave velocity measurement method of AE, the AW method shows the following advantages: A continuous AE signal with small attenuation, no crosstalk and a fixed waveform can be obtained by the AW method, which is more advantageous to distinguish the first arrival time of the acoustic wave and calculate the wave velocity of AE more accurately; the AE signal measured by the AW method has the characteristics of a high frequency and large amplitude, which is easy to distinguish from the noise signal with the characteristics of a low frequency and small amplitude; and the dispersion of the AE wave velocity measured by the $\mathrm{AW}$ method is smaller, which is more suitable for the measurement of the AE wave velocity of an asphalt mixture.

Keywords: asphalt mixture; acoustic emission; wave velocity; arbitrary wave method; time-domain signal; frequency distribution

\section{Introduction}

As a multi-phase composite material, asphalt mixtures cause a series of problems under the action of the external environment and vehicle load. The pavement performance of asphalt mixtures affects their service safety and life directly. The evaluation of the pavement performance of asphalt mixtures is mainly based on laboratory mechanical tests. These laboratory mechanics test methods are used to evaluate and analyze asphalt mixtures from a macroscopic perspective.

In recent years, some researchers have tried to apply acoustic emission (AE) technology to the pavement performance evaluation of asphalt mixtures and characterize and analyze asphalt mixtures from a microscopic point of view. In terms of low-temperature cracking, AE technology was used to study the low-temperature fracture process zone and creep damage zone of asphalt mixtures [1,2]. At the same time, AE technology has also been proved to have advantages in characterizing the low-temperature fracture of recycled and modified asphalt mixtures [3,4]. Buttlar et al. [5,6] proposed two characteristic temperatures $\left(\mathrm{T}_{\mathrm{EMB}}\right.$ and $\mathrm{T}_{\mathrm{MAX}}$ ) based on $\mathrm{AE}$, and these two characteristic temperatures are 
used to analyze and evaluate the low-temperature performance of field asphalt pavement samples [7,8]. Wei et al. [9] studied the dynamic evolution process of low-temperature cracking of asphalt mixtures by using AE technology and the discrete element simulation method. In terms of fatigue damage, AE technology was used to monitor the self-healing ability of asphalt mixtures [10]. At the same time, AE b-value [11], k-clustering [12] and fractal theory [13] were used to explore the fatigue damage process and failure characteristics of asphalt mixture. Liang et al. [14] established a correlation between the fracture damage of an asphalt mixture under a freeze-thaw cycle and its AE signal. In terms of aging, AE technology was used to evaluate the road performance of asphalt mixtures with different aging levels [15,16]. Recently, the characteristics of moisture damage of asphalt mixtures have attracted researchers' attention. AE technology was used to monitor the internal damage, crack type, fracture mode and other characteristics of a steel slag permeable asphalt mixture under compression and splitting [17-20].

Acoustic waves are usually collected by AE or an ultrasonic instrument. Under the action of external factors, the AE signal will be generated and propagated inside the material. The AE wave velocity can be obtained by calculating the distance between acoustic sensors and the time difference of acoustic waves received by the sensors. Due to the differences in composition, homogeneity and property of materials, different materials have their own AE wave velocity range. McGovern et al. [21,22] monitored the propagation characteristics (wave velocity and attenuation) of AE in asphalt mixture. Due to the complex composition of asphalt mixtures, the transmission path and speed of AE in asphalt mixtures are very different. AE wave velocity can not only reflect the internal damage and structural characteristics of the material, but also plays an important role in the calculation of a source location.

However, the current research on the AE wave velocity mainly focuses on rock. The wave velocity in different directions is anisotropic, which can be used to study the damage development and mechanism of marble [23]. In addition, the existence of natural fractures and bedding reduced the wave velocity and mechanical strength of the rock [24]. Under different temperatures and water environments, there is a correlation between the wave velocity and hydraulic properties (permeability and diffusivity) $[25,26]$. The micro-structure and macro-pores in rock mass have a significant impact on the propagation characteristics of acoustic waves such as the wave velocity, wave frequency and attenuation $[27,28]$. For the measurement method of the rock wave velocity, researchers proposed the correction method of the rock mass integrity index [29], the particle flow model analysis method of the rock wave velocity varying with stress [30] and the sparse sensor network monitoring method of the rock mass surface wave velocity [31].

In addition to rocks, wave velocity characterization and test methods of other materials have also attracted researchers' attention. The material composition, structural parameters and cracks in reinforced concrete slabs all affect the wave velocity and propagation of AE [32], and the AE wave velocity of corroded concrete drops sharply [33]. For composite materials, the differences in structural layers, elastic modulus and density affect the propagation velocity of the AE wave [34,35]. In the characteristic medium, the AE wave velocity in liquid nitrogen [36] and natural fat [37] has also attracted researchers' attention.

To sum up, the research on AE wave velocity is mainly in the field of rock and concrete materials. Although some researchers have begun to explore the application of AE technology in asphalt pavement materials, the research scope mainly concerns the combination of the mechanical test method and the AE monitoring method to characterize the pavement performance of asphalt mixtures, and the exploration of the AE wave velocity is very limited. Compared with rock and concrete materials, the composition of asphalt pavement materials is more complex, and the material properties show typical heterogeneity, which makes the propagation speed and propagation characteristics of AE in asphalt pavement materials more complex and variable. Therefore, exploration of the wave velocity measurement method with fewer influencing factors and less discreteness is helpful to better understand the AE propagation mechanism and material properties 
of asphalt pavement. In this paper, an arbitrary wave (AW) method is proposed and designed to measure the $\mathrm{AE}$ wave velocity of an asphalt mixture. Then, the initial $\mathrm{AE}$ wave velocity in an asphalt mixture beam is measured by the pencil lead break (PLB) method, the automatic sensor test (AST) method and the AW method. Finally, the dispersion of the initial wave velocity, the time-domain signal and the frequency distribution of $\mathrm{AE}$ measured by the three methods are compared and analyzed.

\section{Materials and Methods}

\subsection{Test Materials}

In this study, the AC-25 asphalt mixture was selected for the wave velocity test. The coarse aggregate is limestone, the fine aggregate is machine-made sand, the asphalt is 70\# matrix petroleum asphalt and the filler is limestone mineral powder. The selected materials were tested before use, and all met the requirements of specifications [38]. The mix proportion of the asphalt mixture was designed according to the specification [39]. The grading curve of the aggregate designed in this experiment is shown in Figure 1.

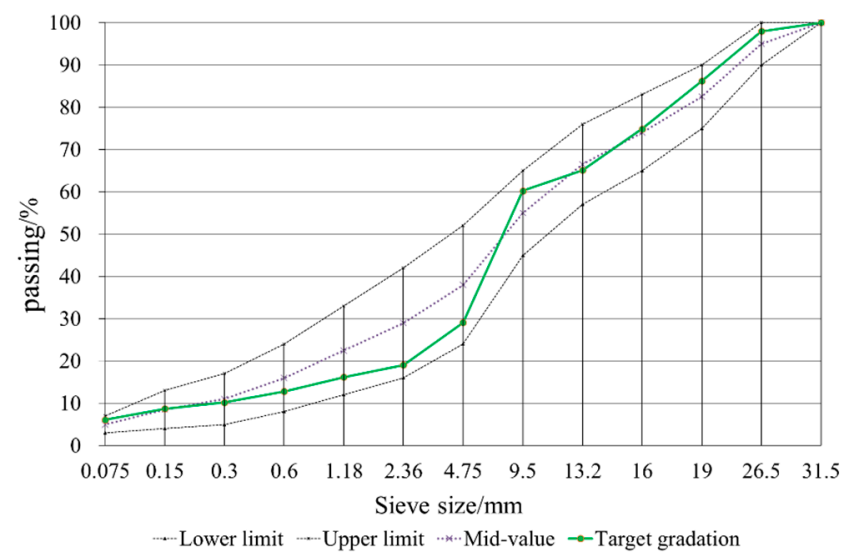

Figure 1. Grading curve of AC-25.

The prepared source materials were mixed at $160{ }^{\circ} \mathrm{C}$ in a mixer. The forming machine was used to make the rutting plate $(300 \mathrm{~mm} \times 300 \mathrm{~mm} \times 50 \mathrm{~mm})$, and then the rutting plates were cut into $250 \mathrm{~mm} \times 35 \mathrm{~mm} \times 30 \mathrm{~mm}$ beam specimens (Figure 2).

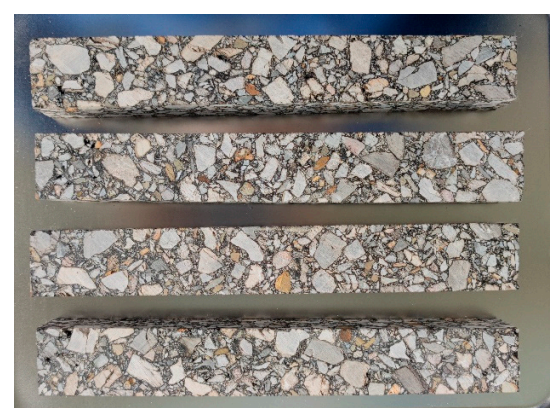

Figure 2. Asphalt mixture beams of AC-25.

\subsection{Test Equipment}

The full-information AE acquisition and signal analysis system with the model DS516C was used in this test (Figure 3). The analysis system can not only collect the AE signal in real time, but also analyzes the waveform of the acquired signal. The signal sampling rate in this test was $3 \mathrm{MHz}$. Because the threshold of the waveform signal was adjusted after the test, the threshold was preset to $100 \mathrm{mV}$ in the acquisition setting, which can prevent the useful AE signal from being missed. The AE sensor of RS-2A with the frequency range of $50-400 \mathrm{kHz}$ and center frequency of $150 \mathrm{kHz}$ was selected in this test. The gain of the 
pre-amplifier was set to $40 \mathrm{~dB}$. High-vacuum grease is used as a coupling agent to couple the sensor with the specimen.

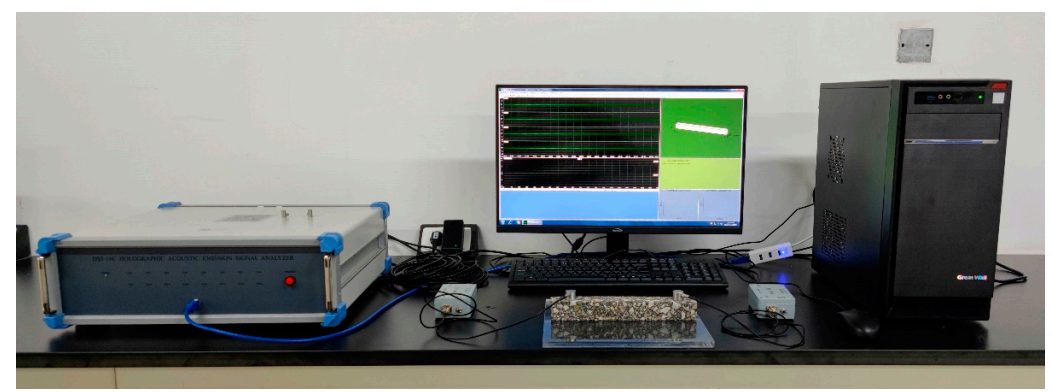

Figure 3. AE signal acquisition and analysis system.

\section{Measurement Method of AE Wave Velocity}

\subsection{PLB Method}

The PLB method is the most widely used method for measuring the wave velocity at present. The operation method of the PLB method is as follows: One AE sensor is arranged at the left and right ends of the specimen, and then the pencil lead is broken at a certain position between the sensors (Figure 4). The AE signals generated by each PLB test are recorded by the $\mathrm{AE}$ acquisition system through sensor 1 and sensor 2, respectively, and the $\mathrm{AE}$ waveform is recorded in real time through the monitor.

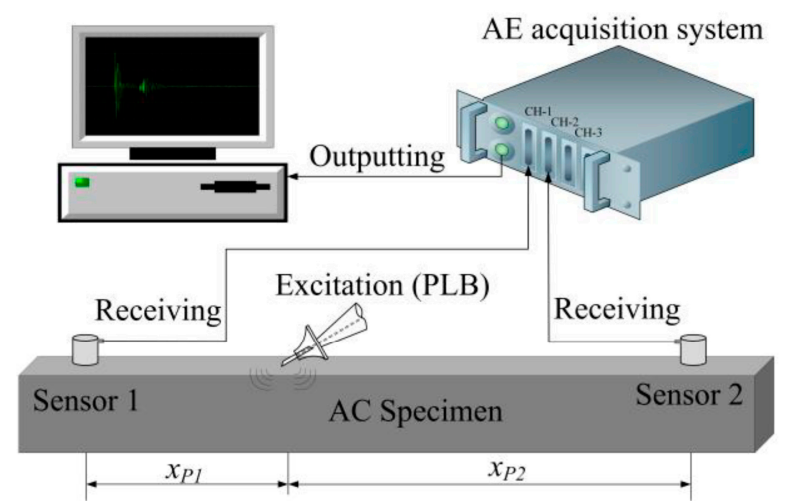

Figure 4. Measurement of the wave velocity by the PLB method.

The AE wave velocity can be calculated according to the distance difference between the lead breaking point (AE source) and the two sensors and the time difference between the $\mathrm{AE}$ signal received by two sensors. The calculation formula of the $\mathrm{AE}$ wave velocity $\left(v_{P}\right)$ by the PLB method is as follows:

$$
v_{P}=\left(x_{P 2}-x_{P 1}\right) /\left(t_{P 2}-t_{P 1}\right)
$$

where $x_{P 1}$ and $x_{P 2}$ are the distances between the $\mathrm{AE}$ source and sensor 1 and sensor 2, respectively; $t_{P 1}$ and $t_{P 2}$ are the arrival time of the AE signal to sensor 1 and sensor 2, respectively.

\subsection{AST Method}

The AST method is used to measure the AE wave velocity by using the pulse excitation and receiving function of the AE sensor. The specific operation method of AST is as follows: Two AE sensors are arranged at both ends of the specimen. Sensor 1 is used for pulse excitation, sensor 2 is used for pulse receiving, and the AE waveform is recorded in real time through the monitor (Figure 5). 


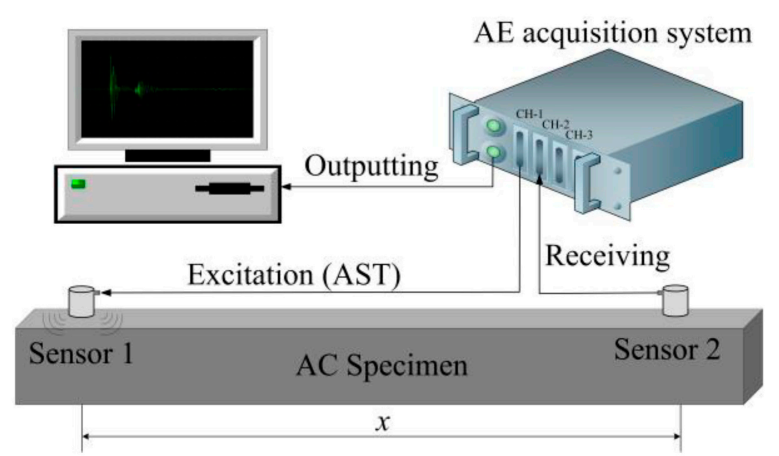

Figure 5. Measurement of the wave velocity by the AST method.

The AE wave velocity can be calculated according to the distance between the two sensors and the time difference between the excitation time of the pulse excitation sensor and the receiving time of the pulse signal. The calculation formula of the $\mathrm{AE}$ wave velocity $\left(v_{A S T}\right)$ by the AST method is as follows:

$$
v_{A S T}=x /\left(t_{A S T 2}-t_{A S T 1}\right)
$$

where $x$ is the distance between two sensors; $t_{A S T 1}$ and $t_{A S T 2}$ are the excitation time of the pulse excitation sensor and the receiving time of the pulse receiving sensor, respectively.

\subsection{AW Method}

The AW method is used to design and write arbitrary waveform data by computer and modulate the AW signal generated by the data. Then the modulated arbitrary waveform is input into the $\mathrm{AE}$ acquisition system. The $\mathrm{AE}$ acquisition system excites the arbitrary waveform to the specimen through the excitation sensor (sensor 3). At the same time, the receiving sensor (sensor 1 and sensor 2) is used to receive arbitrary waveforms and output the received waveforms to the monitor through their respective channels. Figure 6 shows the measurement method of the AE wave velocity by the AW method.

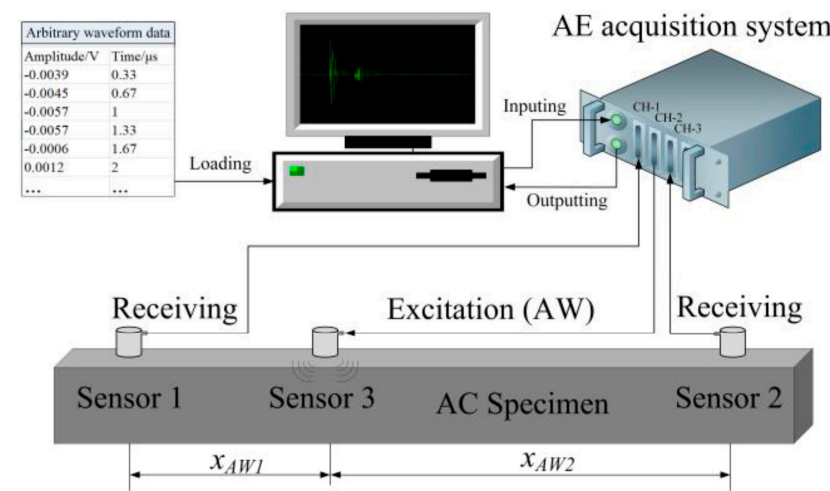

Figure 6. Measurement of the wave velocity by the AW method.

The AE wave velocity can be calculated according to the distance difference between the excitation sensor (sensor 3 ) and the receiving sensor (sensor 1 and sensor 2 ) and the time difference between the AE signal received by the two receiving sensors. The calculation formula of the $\mathrm{AE}$ wave velocity $\left(v_{A W}\right)$ by the $\mathrm{AW}$ method is as follows:

$$
v_{A W}=\left(x_{A W 1}-x_{A W 2}\right) /\left(t_{A W 1}-t_{A W 2}\right)
$$

where $x_{A W 1}$ and $x_{A W 2}$ are the distances between the excitation sensor and the two receiving sensors, respectively; $t_{A W 1}$ and $t_{A W 2}$ are the time when AE signals arrive at the two receiving sensors, respectively. 


\section{Measurement Results of AE Wave Velocity}

\subsection{PLB Method}

In order to obtain the accurate initial velocity of $\mathrm{AE}$ as much as possible, the $\mathrm{AE}$ velocity measurement based on the PLB method was carried out considering the lead breaking position, threshold correction and operation error.

Two AE sensors are arranged on the upper surface of the asphalt mixture beam along the length direction. The two sensors are $50 \mathrm{~mm}$ apart from the left and right ends of the beam, respectively, and the distance between the sensors is $200 \mathrm{~mm}$. Ten lead-breaking experiments were conducted at the position $50 \mathrm{~mm}$ and $150 \mathrm{~mm}$ away from sensor 1 , and $20 \mathrm{AE}$ waveforms were collected. The waveform of each lead breaking was replayed and analyzed, and the first arrival time of the AE wave was determined by threshold correction. In order to avoid the influence of operation error, the maximum and minimum wave velocities of the lead-breaking test at each position were removed, and the remaining 16 wave velocities were taken as the initial wave velocities of AE. Table 1 shows the initial wave velocity of the asphalt mixture beam measured by the PLB method.

Table 1. Measurement results of the wave velocity by the PLB method.

\begin{tabular}{ccc}
\hline Lead Breaking Position ${ }^{\mathbf{1}}(\mathbf{m m})$ & $\mathbf{5 0}$ & $\mathbf{1 5 0}$ \\
\hline & $3191 / 25$ & $3260 / 33$ \\
& $3225 / 40$ & $3225 / 27$ \\
$v_{P}(\mathrm{~m} / \mathrm{s}) /$ Threshold correction value $(\mathrm{mV})$ & $3157 / 23$ & $3333 / 13$ \\
& $3124 / 20$ & $3333 / 26$ \\
& $3030 / 26$ & $3703 / 5$ \\
Average wave velocity (m/s) & $3061 / 14$ & $3370 / 30$ \\
\end{tabular}

${ }^{1}$ Lead breaking position: the position from sensor 1.

\subsection{AST Method}

Two AE sensors were arranged $50 \mathrm{~mm}$ away from both ends of the asphalt mixture beam, and the distance between the two sensors was $200 \mathrm{~mm}$. Sensor 1 was used for pulse excitation and sensor 2 received the pulse. One pulse signal was excited each time, and the excitation was conducted 10 times in total. Then, sensor 2 was used for pulse excitation, and sensor 1 received the pulse signal, which was also excited 10 times. Therefore, $20 \mathrm{AE}$ waveform signals were collected by the AST method. The time duration of each pulse was $5 \mu \mathrm{s}$ and the period was $50 \mu \mathrm{s}$. The time interval between pulse signals was $1000 \mathrm{~ms}$.

Because the pulse signal excited by the sensor is very strong, the signal will crosstalk to the receiving channel, so the system cannot correctly identify the first arrival time of the AE wave. Therefore, first of all, the collected signal waveform was played back, and the correct threshold was set. Then, the crosstalk signal was blank processed, so that the system can accurately identify the first arrival time of the AE wave. Finally, the AE wave velocity was calculated. Figure 7 shows the AE waveform of the crosstalk signal before and after the blanking process.

In order to avoid systematic errors, the first and last AST test results were eliminated, and the wave velocities calculated from the remaining 16 AST tests were taken as the initial wave velocities of AE. Table 2 shows the initial wave velocity of the asphalt mixture beam measured by the AST method. 


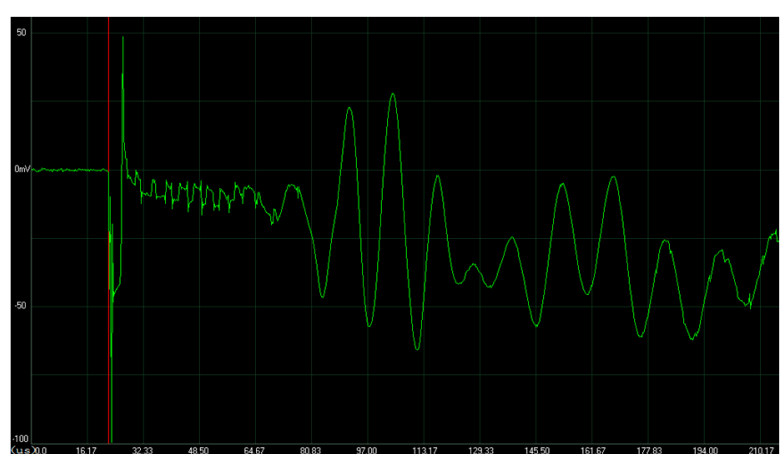

(a)

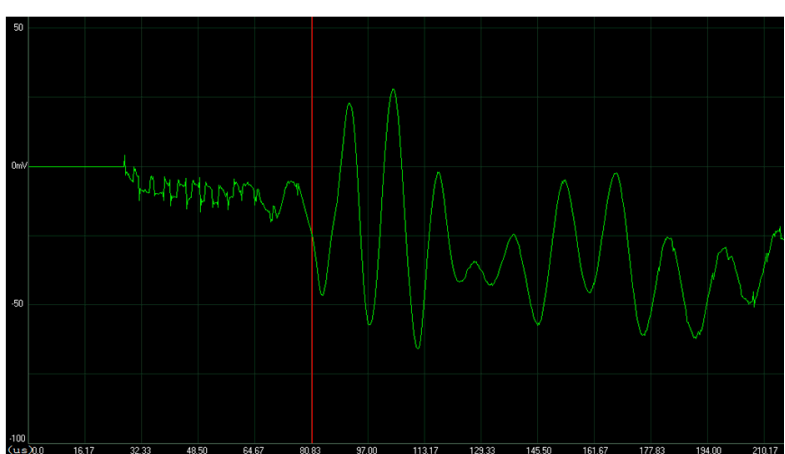

(b)

Figure 7. (a) AE waveforms containing crosstalk signals; (b) AE waveform of the crosstalk signal after the blanking process.

Table 2. Measurement results of the wave velocity by the AST method.

\begin{tabular}{ccc}
\hline Excitation Sensor & $\mathbf{1}$ & $\mathbf{2}$ \\
\hline & 3095 & 3161 \\
& 3095 & 3177 \\
$v_{A S T}(\mathrm{~m} / \mathrm{s})$ & 3161 & 3144 \\
& 3080 & 3161 \\
& 3095 & 3177 \\
& 3080 & 3144 \\
& 3080 & 3161 \\
Threshold correction value $(\mathrm{mV})$ & 3161 & 20 \\
Range of blanking time $(\mu \mathrm{s})$ & 20 & $7-64$ \\
Average wave velocity $(\mathrm{m} / \mathrm{s})$ & $8-66$ & \\
\hline
\end{tabular}

\subsection{AW Method}

In this experiment, a sine wave with a frequency of $150 \mathrm{kHz}$ and an amplitude of $5000 \mathrm{mv}$ was designed and modulated as an arbitrary waveform to excite the asphalt mixture beam (Figure 8). The emission type of AW was equal interval emission, and the interval time was $1000 \mathrm{~ms}$. The length of the waveform of each AW emitted by the system was $500 \mu \mathrm{s}$.

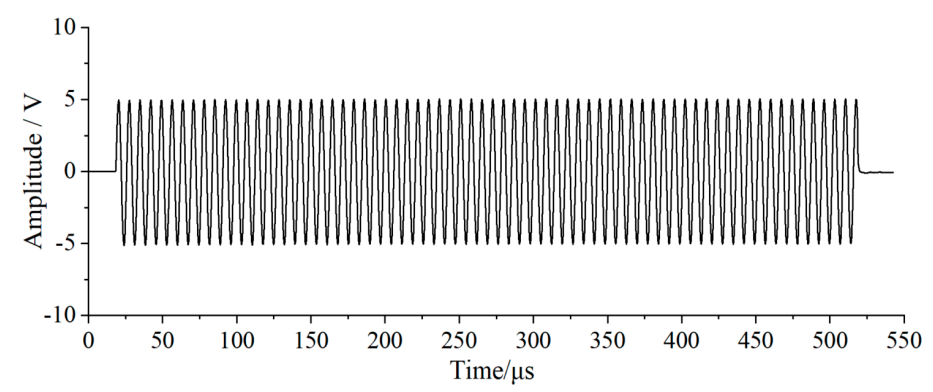

Figure 8. Sine wave after modulation.

Three AE sensors were arranged on the upper surface of the asphalt mixture beam along the length direction. The two sensors were the receiving sensors (sensor 1 and sensor 2), which were $50 \mathrm{~mm}$ away from the left and right ends of the beam, respectively, and the distance between the sensors was $200 \mathrm{~mm}$. The third sensor was the excitation sensor (sensor 3). Ten arbitrary waves were excited at $50 \mathrm{~mm}$ and $150 \mathrm{~mm}$, and a total of 20 AEs were collected. The waveform of each AW excitation was replayed and analyzed, and the first arrival time of the AE wave was determined by threshold correction.

The accuracy of the excitation results of the modulated sine wave was verified before the formal measurement of the wave velocity. Fast Fourier transform (FFT) was applied to 
the waveform results generated by AW excitation to obtain the corresponding spectrogram (Figure 9). It can be seen from the figure that the frequency distribution was concentrated in the range of $150 \mathrm{kHz}$, which proves that the modulated sine wave has a good excitation effect as an AW.

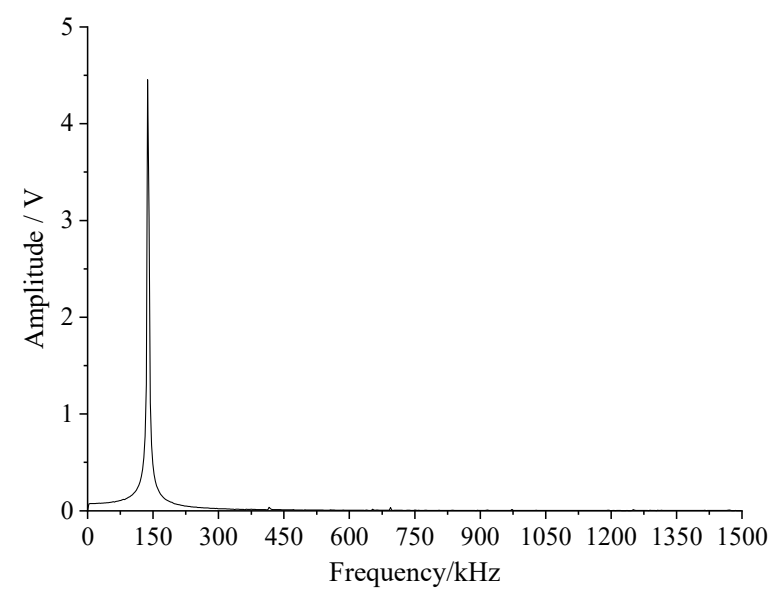

Figure 9. The spectrum of AW.

In order to avoid systematic errors, the first and last AW test results of each excitation position were eliminated, and the wave velocities calculated from the remaining $16 \mathrm{AW}$ tests were taken as the initial wave velocities of AE. Table 3 shows the initial wave velocity of the asphalt mixture beam measured by the AW method.

Table 3. Measurement results of the wave velocity by the AW method.

\begin{tabular}{|c|c|c|}
\hline Excitation Position ${ }^{1}(\mathrm{~mm})$ & 50 & 100 \\
\hline \multirow{8}{*}{$v_{A S T}(\mathrm{~m} / \mathrm{s})$} & 3157 & 3192 \\
\hline & 3157 & 3192 \\
\hline & 3157 & 3157 \\
\hline & 3124 & 3157 \\
\hline & 3124 & 3124 \\
\hline & 3124 & 3124 \\
\hline & 3191 & 3124 \\
\hline & 3191 & 3157 \\
\hline Threshold correction value $(\mathrm{mV})$ & 5 & 5 \\
\hline Average wave velocity (m/s) & \multicolumn{2}{|c|}{3153.3} \\
\hline
\end{tabular}

${ }^{1}$ Excitation position: the position from sensor 1 .

\section{Analysis and Discussion}

\subsection{Dispersion of Initial Wave Velocity}

Comparing the wave velocity measured by the three $\mathrm{AE}$ wave velocity measurement methods (Figure 10a) and their standard deviation (Figure 10b), it can be seen that the initial wave velocity distribution of AE measured by the PLB method is $3000-3800 \mathrm{~m} / \mathrm{s}$ and the standard deviation is close to 200, which indicates that the initial wave velocity of AE measured by the PLB method presents a large dispersion. The initial wave velocities of AE measured by the AST and AW methods are concentrated in the range of 3000-3200 m/s and the standard deviations are 37.7 and 26.3, respectively, which are far less than the standard deviation measured by PLB, indicating that the dispersion of the initial wave velocity measured by the AW and AST methods is small. 


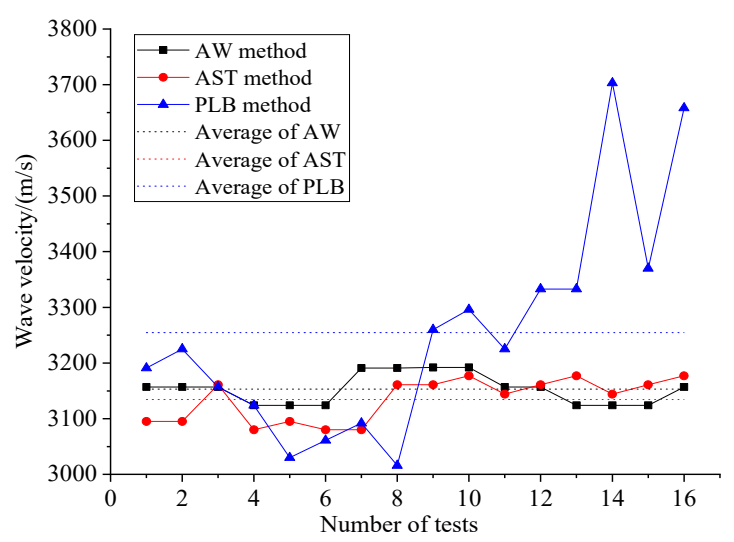

(a)

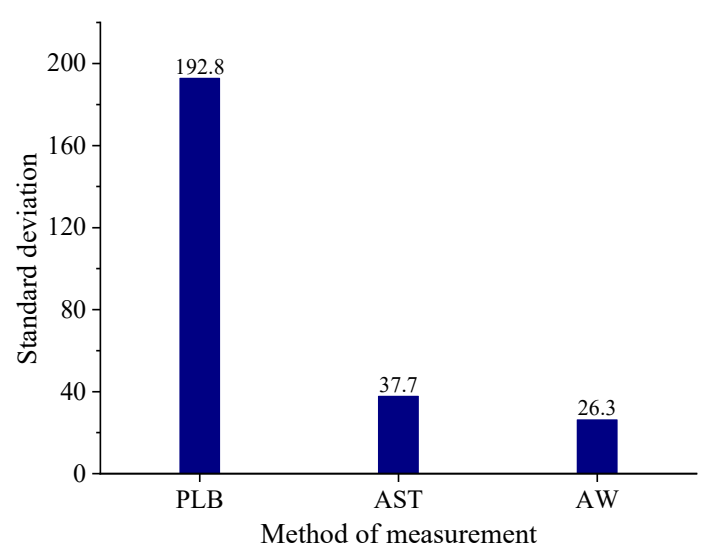

(b)

Figure 10. (a) Results of three wave velocity measurement methods. (b) Standard deviation of three wave velocity measurement methods.

\subsection{Time-Domain Signal of $A E$}

The time-domain signals of $\mathrm{AE}$ obtained by the three wave velocity measurement methods are shown in Figures 11-13. Figure 11 shows the time-domain signal of AE generated by two different lead-breaking positions in the PLB method. It can be seen that lead breaking produces a burst $\mathrm{AE}$ signal and attenuates rapidly. At the same time, the time-domain waveforms generated by different lead-breaking positions are quite different. Figure 12 shows the time-domain signal of AE generated by two different excitation sensors in the AST method. It can be seen that the AST method can generate a burst AE signal, and the attenuation is smaller than that of the PLB method. In addition to the difference in the crosstalk waveform amplitude, different excitation sensors produce the same $\mathrm{AE}$ waveform in the AST method. Figure 13 shows the time-domain signal of AE generated by two different excitation positions in the AW method. It can be seen that AW excitation produces a continuous AE signal. The continuous AE signal has a long duration and low attenuation. At the same time, there is no significant difference in the waveform generated by the two different excitation positions.
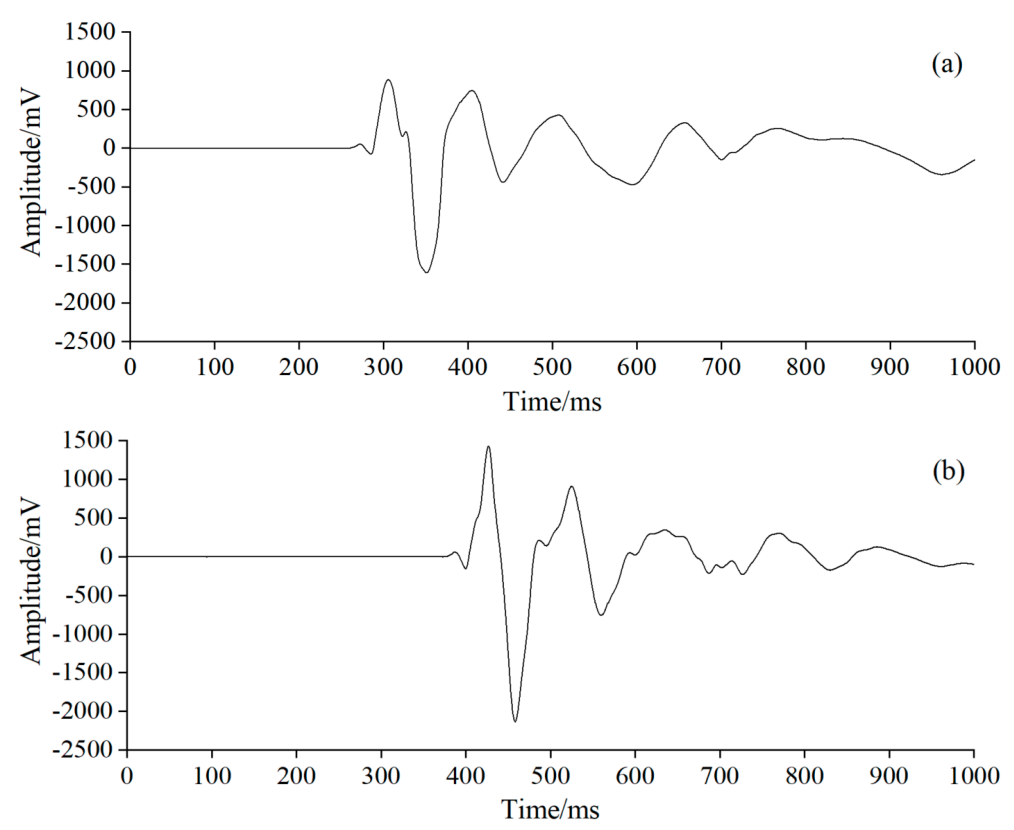

Figure 11. The time-domain waveform of AE by the PLB method: (a) Lead-breaking position is $50 \mathrm{~mm}$; (b) lead-breaking position is $150 \mathrm{~mm}$. 

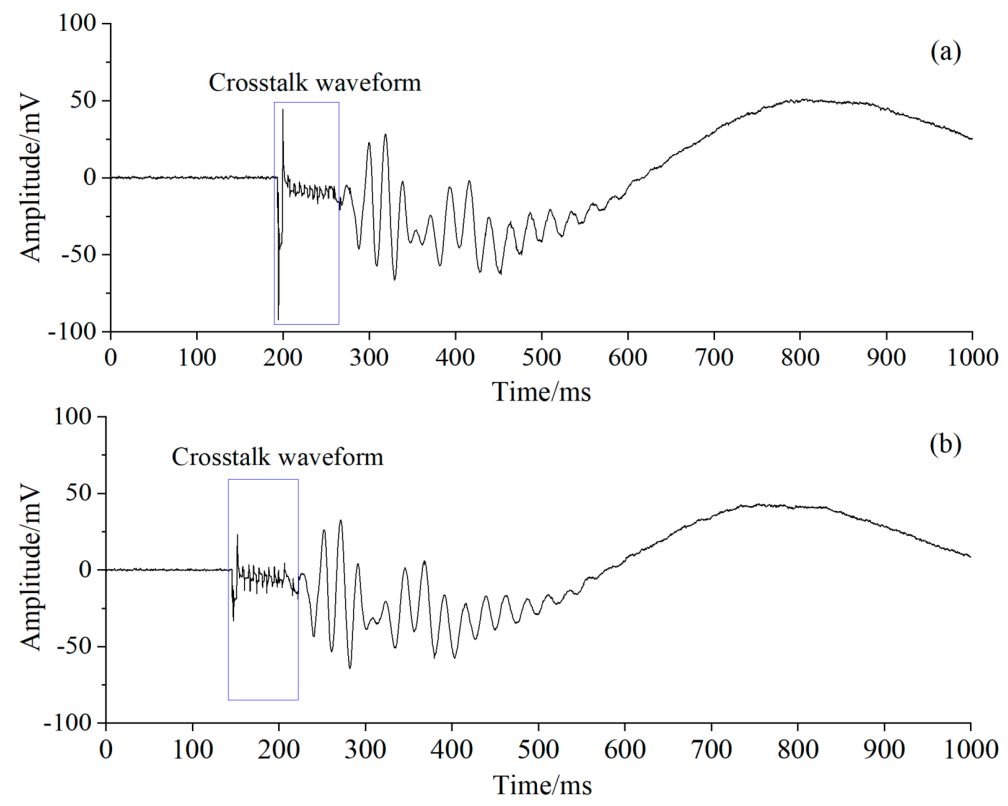

Figure 12. The time-domain waveform of AE by the AST method: (a) Excitation sensor 1; (b) excitation sensor 2 .
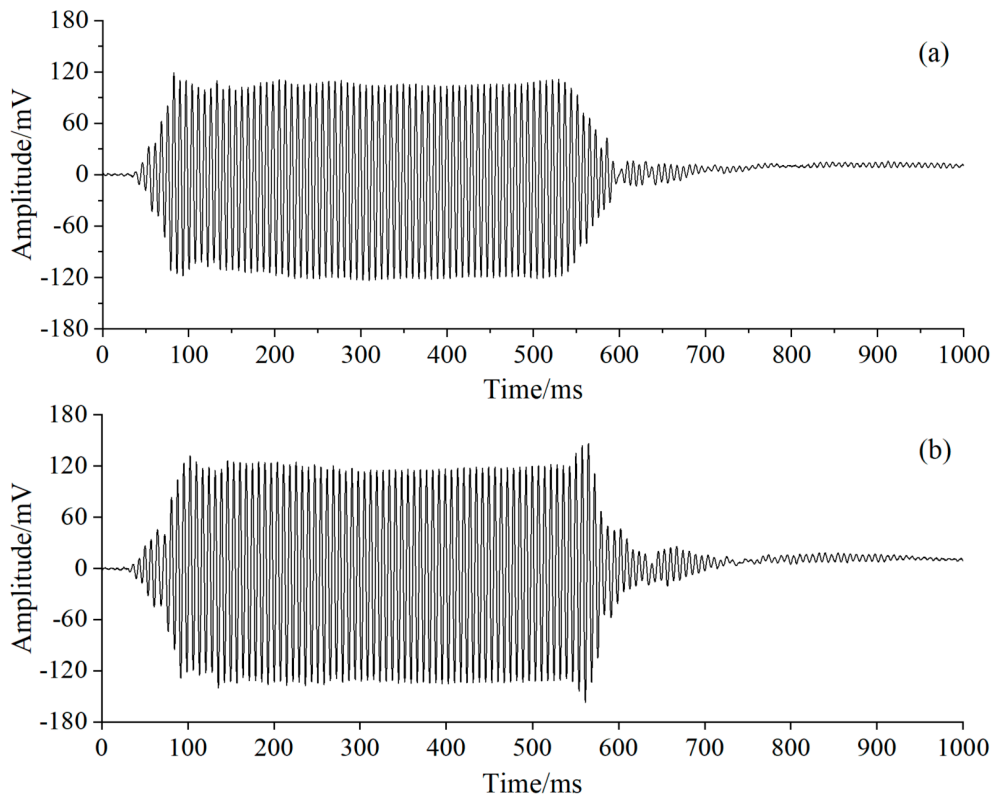

Figure 13. The time-domain waveform of AE by the AW method: (a) Excitation position is $50 \mathrm{~mm}$; (b) excitation position is $150 \mathrm{~mm}$.

\subsection{Frequency-Domain Signal of $A E$}

The time-domain signal reflects the intensity and attenuation of AE. However, in addition to the AE signal, the collected signal also includes the noise signal caused by artificial operation, the external environment and the system. The noise signal is generally a low-frequency signal, while the AE signal is a high-frequency signal. Therefore, the frequency distribution and characteristics of the AE signal and noise signal can be obtained by frequency analysis of three wave velocity measurement methods. Figures 14-16 show the corresponding spectrum of AE signals obtained by the three wave velocity measurement methods. 

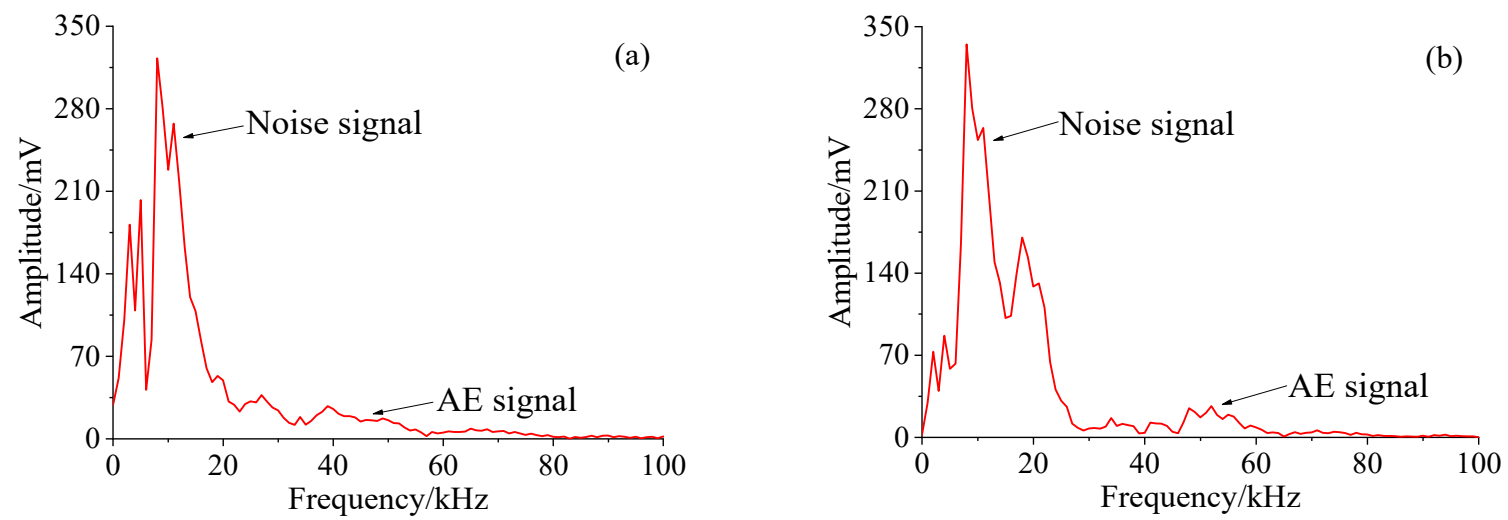

Figure 14. Frequency spectrum of AE by the PLB method: (a) Lead-breaking position is $50 \mathrm{~mm}$; (b) lead-breaking position is $150 \mathrm{~mm}$.
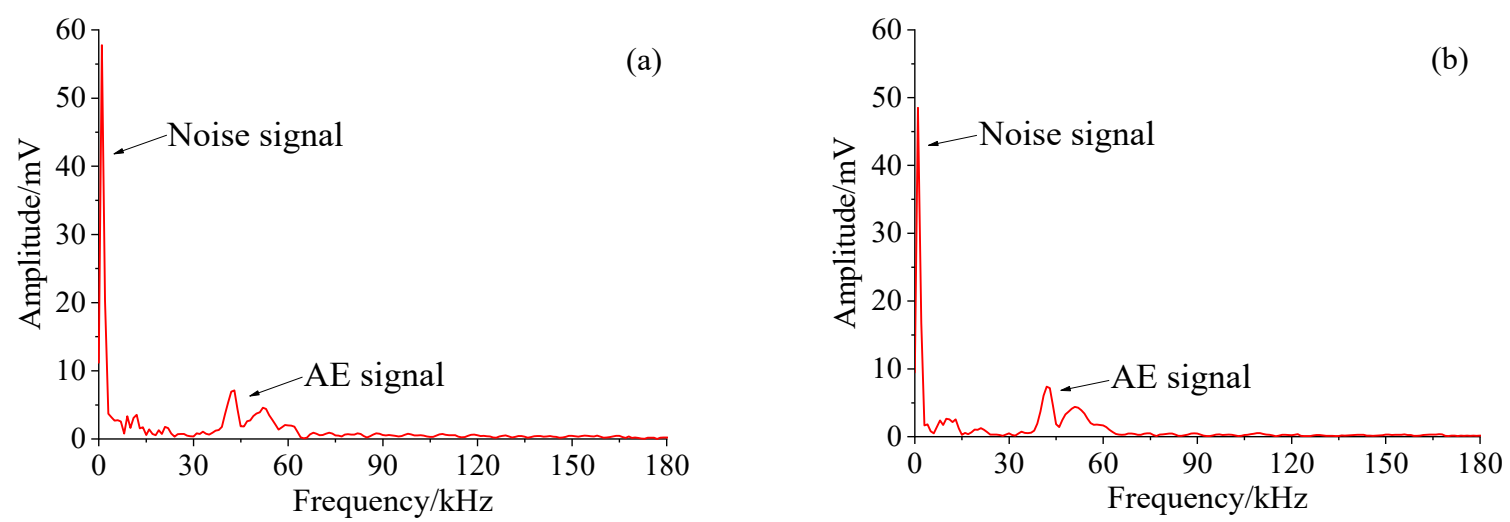

Figure 15. Frequency spectrum of AE by the AST method: (a) Excitation sensor 1; (b) excitation sensor 2.
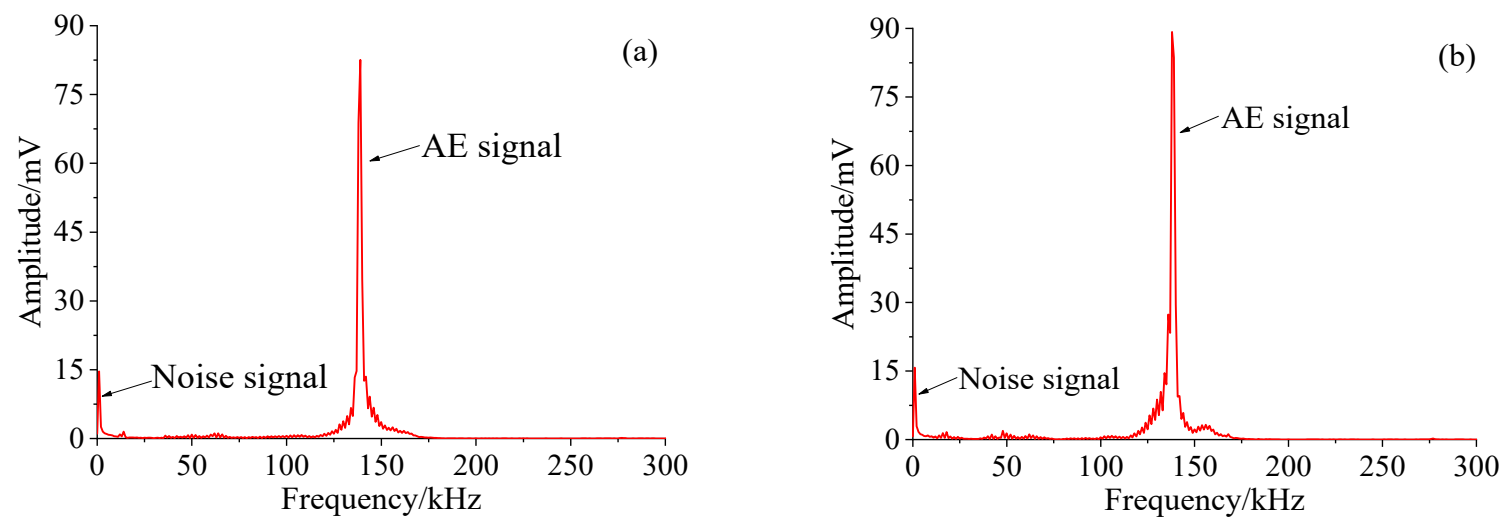

Figure 16. Frequency spectrum of AE by the AW method: (a) Excitation position is $50 \mathrm{~mm}$; (b) excitation position is $150 \mathrm{~mm}$.

Figure 14 shows the AE spectrum generated by two lead-breaking positions in the PLB method. It can be seen from the figure that the frequency range of the noise signal and $\mathrm{AE}$ signal cannot be clearly distinguished. The frequency distribution of the noise signal is $0-30 \mathrm{kHz}$, and the peak amplitude is $335 \mathrm{mV}$. The frequency distribution of the AE signal is $30-60 \mathrm{kHz}$, and the peak amplitude is $25 \mathrm{mV}$. There are obvious differences in frequency characteristics of AE signals between the two lead-breaking positions. Figure 15 shows the AE spectrum generated by two excitation sensors in the AST method. As can be seen from the figure, the frequency distribution of the noise signal and AE signal can be easily distinguished. The frequency distribution of the noise signal is $0-15 \mathrm{kHz}$, and the peak amplitude is $58 \mathrm{mV}$. The frequency distribution of the AE signal is $40-60 \mathrm{kHz}$, and the peak 
amplitude is $8 \mathrm{mV}$. The difference in frequency distribution and amplitude of AE generated by the two excitation sensors is very small. Figure 16 shows the AE spectrum generated by two excitation positions in the AW method. As can be seen from the figure, the frequency distribution of the noise signal and $\mathrm{AE}$ signal are very easy to distinguish. The frequency distribution of the noise signal is $0-10 \mathrm{kHz}$, and the peak amplitude is close to $15 \mathrm{mV}$. The frequency distribution of the AE signal is $120-170 \mathrm{kHz}$, and the peak amplitude is close to $58 \mathrm{mV}$. The frequency distribution and amplitude of $\mathrm{AE}$ generated by the two excitation sensors are consistent.

\subsection{Discussion}

By comparing and analyzing the initial wave velocity and corresponding AE signals measured by the three methods, it can be concluded that there are differences in wave velocities and signal characteristics between different methods. Table 4 shows the comparison and analysis results of the three $\mathrm{AE}$ wave velocity measurement methods.

Table 4. Comparison results of three wave velocity measurement methods.

\begin{tabular}{cccc}
\hline Methods & PLB & AST & AW \\
\hline Discreteness & large & small & small \\
Signal types & burst & burst & continuous \\
Degree of attenuation & large & small & small \\
Time-domain waveform & unfixed & fixed & fixed \\
Frequency distribution & unfixed & fixed & fixed \\
Frequency characteristics & high frequency and & high frequency and & high frequency and \\
of AE & small amplitude & small amplitude & large amplitude \\
Frequency characteristics & low frequency and & low frequency and & low frequency and \\
of noise & large amplitude & large amplitude & small amplitude \\
\hline
\end{tabular}

For the PLB method, which is the most widely used method at present because the lead breaking is performed artificially, the AE events produced by each lead breaking are different. Different AE events correspond to different waveforms, so it is necessary to modify the threshold of each lead-breaking waveform when calculating the wave velocity. As can be seen from Table 1, the threshold correction value of each lead breaking is different, which is also the reason for the large dispersion of the initial $\mathrm{AE}$ wave velocity measured by the PLB method. At the same time, the attenuation of the AE signal obtained by the PLB method is large, and its frequency is difficult to distinguish from the noise signal, so it will seriously affect the accuracy of the wave velocity measurement results.

The AE in the AST method is excited by the same sensor, so the AE events generated are the same. Therefore, in the calculation of the wave velocity, only one AE waveform needs to be threshold corrected, and this threshold correction value is applicable to all $\mathrm{AE}$ events in the AST method. So, the initial wave velocity measured by the AST method has little dispersion. However, because the pulse signal excited by the excitation sensor is very strong, the signal will crosstalk to other channels, resulting in the signal collected by the receiving sensor containing a strong crosstalk signal. Therefore, before the first arrival time of the $\mathrm{AE}$ wave is determined, the waveform of the strong crosstalk signal needs to be blanking processed. Since the pulse intensity of each excitation is random, the intensity of the crosstalk signal is different, so the blanking time also needs to be determined for each AE event. Therefore, the AST method is not the best method to measure the AE wave velocity.

In the AW method, the AE signal is generated by the excitation of the modulated AW (sine wave), so there will be no crosstalk signal. In addition, each AE event generated by the AW method is the same, so only one AE signal waveform needs to be threshold corrected. Therefore, the initial wave velocity measured by the AW method has very little dispersion. At the same time, the attenuation of the AE signal obtained by the AW method is small, and the frequency of the AE signal and noise signal is easy to distinguish, which 
is conducive to determining the first arrival time of the $\mathrm{AE}$ wave and the calculation of the $\mathrm{AE}$ wave velocity. Therefore, the AW method has great advantages as a method of measuring the $\mathrm{AE}$ wave velocity.

\section{Conclusions}

A new method, the AW method, was designed for measuring the AE wave velocity of asphalt mixtures, and the $\mathrm{AE}$ wave velocity of an asphalt mixture beam was measured by the AW method and traditional AE wave velocity test methods (the PLB method and the AST method), respectively. By comparing and analyzing the wave velocities measured by the three methods and the corresponding AE signals, the main conclusions are as follows.

By comparing the initial $\mathrm{AE}$ wave velocity obtained by three wave velocity measurement methods, it can be concluded that the dispersion of the initial AE wave velocity $(3100-3200 \mathrm{~m} / \mathrm{s})$ measured by the AW method is the smallest, which is more suitable for the $\mathrm{AE}$ wave velocity measurement of asphalt mixtures.

Comparing the time-domain signals obtained by three wave velocity measurement methods, it can be concluded that the PLB method and the AST method obtain a burst AE signal, while the AW method obtains a continuous AE signal. Signal attenuation was in the order of PLB method > AST method > AW method. The AE waveforms of the PLB method are different at different lead-breaking positions, while the AE waveforms of the AST method and the AW method are the same at different excitation positions.

For the PLB method and the AST method, the frequency spectrum of the noise signal presents the characteristics of a low frequency and a large amplitude, while the frequency spectrum of the AE signal presents the characteristics of a large frequency and a low amplitude. For the AW method, the frequency spectrum of the noise signal is characterized by a low frequency and a small amplitude, while the frequency spectrum of the AE signal is characterized by a high frequency and a large amplitude. The peak amplitude and frequency distribution range of the noise signal was in the order of PLB method $>$ AST method $>$ AW method. The frequency distribution range of the AE signal was in the order of AW method > PLB method > AST method.

The AW method was first proposed and designed to measure the AE wave velocity of an asphalt mixture in this study. Through the wave velocity test and in comparison with the existing wave velocity measurement methods, it is concluded that the AW method is superior in wave velocity measurement of asphalt mixtures. This is a successful attempt. At the same time, this method also provides a new idea for wave velocity measurement of other heterogeneous composites. In future research, this method will be used to explore the $\mathrm{AE}$ wave velocity and propagation mechanism of different gradations and types of asphalt mixture. At the same time, this method will also be used in the calculation of AE source locations.

Author Contributions: Conceptualization, J.L. and L.W.; methodology, J.L.; validation, J.L., Z.Y. and W.W.; formal analysis, J.L.; investigation, J.L., H.L. and K.Z.; resources, J.L. and L.W.; data curation, J.L. and K.Z.; writing—original draft preparation, J.L. and H.L.; writing—review and editing, L.W., W.W. and Z.Y.; visualization, J.L.; supervision, L.W. and J.L.; project administration, L.W.; funding acquisition, L.W. All authors have read and agreed to the published version of the manuscript.

Funding: This research was funded by Beijing major science and technology projects, grant number Z191100008019002.

Conflicts of Interest: The authors declare no conflict of interest.

\section{References}

1. Li, X.; Marasteanu, M. The fracture process zone in asphalt mixture at low temperature. Eng. Fract. Mech. 2010, 77, 1175-1190. [CrossRef]

2. Li, X.; Marasteanu, M.O.; Labuz, J.F.; Williams, R.C. Response Behavior of Asphalt Mixtures at Low Temperatures Under Varying Indirect Tensile Test Loading Conditions. J. Test. Eval. 2011, 39, 611-620. [CrossRef]

3. Hill, B.; Behnia, B.; Hakimzadeh, S.; Buttlar, W.G.; Reis, H. Evaluation of Low-Temperature Cracking Performance of Warm-Mix Asphalt Mixtures. Transport. Res. Rec. 2012, 2294, 81-88. [CrossRef] 
4. Hill, B.; Oldham, D.; Behnia, B.; Fini, E.H.; Buttlar, W.G.; Reis, H. Low-Temperature Performance Characterization of Biomodified Asphalt Mixtures that Contain Reclaimed Asphalt Pavement. Transport. Res. Rec. 2013, 2371, 49-57. [CrossRef]

5. Buttlar, W.G.; Behnia, B.; Reis, H.M. An Acoustic Emission-Based Test to Determine Asphalt Binder and Mixture Embrittlement Temperature; NCHRP-IDEA: Washington, DC, USA, 2011; pp. 1-47. Available online: https://trid.trb.org/view/1127542 (accessed on 5 September 2021).

6. Buttlar, W.G.; Reis, H.; Behnia, B. Development and Implementation of the Asphalt Embrittlement Analyzer; NCHRP IDEA: Washington, DC, USA, 2015; pp. 1-30. Available online: https:/ / trid.trb.org/view/1405345 (accessed on 5 September 2021).

7. Behnia, B.; Buttlar, W.G.; Reis, H. Cooling cycle effects on low temperature cracking characteristics of asphalt concrete mixture. Mater. Struct. 2014, 47, 1359-1371. [CrossRef]

8. Behnia, B.; Buttlar, W.G.; Reis, H. Nondestructive Acoustic Emission Test to Evaluate Thermal Damage in Asphalt Concrete Materials. J. Test. Eval. 2018, 46, 118-126. [CrossRef]

9. Wei, H.; Li, J.; Wang, F.; Zheng, J.; Tao, Y.; Zhang, Y. Numerical investigation on fracture evolution of asphalt mixture compared with acoustic emission. Int. J. Pavement Eng. 2021, 1-11. [CrossRef]

10. Behnia, B.; Reis, H. Self-healing of thermal cracks in asphalt pavements. Constr. Build. Mater. 2019, 218, 316-322. [CrossRef]

11. Qiu, X.; Xu, J.; Xiao, S.; Yang, Q. Acoustic emission parameters and waveforms characteristics of fracture failure process of asphalt mixtures. Constr. Build. Mater. 2019, 215, 135-147. [CrossRef]

12. Cai, X.; Shi, C.; Chen, X.; Yang, J. Identification of damage mechanisms during splitting test on SFP at different temperatures based on acoustic emission. Constr. Build. Mater. 2021, 270, 121391. [CrossRef]

13. Qiu, X.; Xu, J.; Xu, W.; Xiao, S.; Wang, F.; Yuan, J. Characterization of fatigue damage mechanism of asphalt mixtures with acoustic emission. Constr. Build. Mater. 2020, 240, 117961. [CrossRef]

14. Liang, C.; Ma, J.; Zhou, P.; Ma, G.; Xu, X. Fracture Damage Properties of SBS-Modified Asphalt Mixtures Reinforced with Basalt Fiber after Freeze-Thaw Cycles Using the Acoustic Emission Approach. Appl. Sci. 2020, 10, 3301. [CrossRef]

15. Sun, Z.; Behnia, B.; Buttlar, W.G.; Reis, H. Acoustic emission quantitative evaluation of rejuvenators to restore embrittlement temperatures to oxidized asphalt mixtures. Constr. Build. Mater. 2016, 126, 913-923. [CrossRef]

16. Benaboud, S.; Takarli, M.; Pouteau, B.; Allou, F.; Dubois, F.; Hornych, P.; Nguyen, M.L. Fatigue damage monitoring and analysis of aged asphalt concrete using acoustic emission technique. Road Mater. Pavement 2021, 22, S592-S603. [CrossRef]

17. Jiao, Y.; Fu, L.; Shan, W.; Liu, S. Damage fracture characterization of pervious asphalt considering temperature effect based on acoustic emission parameters. Eng. Fract. Mech. 2019, 210, 147-159. [CrossRef]

18. Jiao, Y.; Liu, S.; Fu, L.; Shan, W. Fracture Monitoring of SBS and Crumb Rubber Modified Porous Asphalt Mixtures under Compression and Splitting Testing Using Acoustic Emission Technique. J. Mater. Civil Eng. 2019, 31, 4019063. [CrossRef]

19. Zhu, B.; Liu, H.; Li, W.; Wu, C.; Chai, C. Fracture Behavior of Permeable Asphalt Mixtures with Steel Slag under Low Temperature Based on Acoustic Emission Technique. Sensors 2020, 20, 5090. [CrossRef]

20. Xu, W.; Chen, B.; Chen, X.; Chen, C. Influence of aggregate size and notch depth ratio on fracture performance of steel slag pervious concrete. Constr. Build. Mater. 2021, 273, 122036. [CrossRef]

21. Mcgovern, M.E.; Behnia, B.; Buttlar, W.G.; Reis, H. Concrete Testing: Characterisation of oxidative ageing in asphalt concretePart 1: Ultrasonic velocity and attenuation measurements and acoustic emission response under thermal cooling. Insight 2013, 55, 596-604. [CrossRef]

22. Mcgovern, M.E.; Behnia, B.; Buttlar, W.G.; Reis, H. Use of Nonlinear Acoustic Measurements for Estimation of Fracture Performance of Aged Asphalt Mixtures. Transport. Res. Rec. 2017, 2631, 11-19. [CrossRef]

23. Wu, Z.; Wang, Z.; Fan, L.; Weng, L.; Liu, Q. Micro-failure process and failure mechanism of brittle rock under uniaxial compression using continuous real-time wave velocity measurement. J. Cent. South Univ. 2021, 28, 556-571. [CrossRef]

24. Zuo, J.; Wei, X.; Shi, Y.; Liu, C.; Li, M.; Wong, R.H.C. Experimental study of the ultrasonic and mechanical properties of a naturally fractured limestone. Int. J. Rock Mech. Min. 2020, 125, 104162. [CrossRef]

25. Jiang, G.; Zuo, J.; Ma, T.; Wei, X.; Fulignati, P. Experimental Investigation of Wave Velocity-Permeability Model for Granite Subjected to Different Temperature Processing. Geofluids 2017, 2017, 1-10. [CrossRef]

26. Ahrens, B.; Duda, M.; Renner, J. Relations between hydraulic properties and ultrasonic velocities during brittle failure of a low-porosity sandstone in laboratory experiments. Geophys. J. Int. 2018, 212, 627-645. [CrossRef]

27. Zhou, X.; Fan, L.; Wu, Z. Effects of Microfracture on Wave Propagation through Rock Mass. Int. J. Geomech. 2017, 17, 4017072. [CrossRef]

28. Sarout, J.; Cazes, E.; Delle Piane, C.; Arena, A.; Esteban, L. Stress-dependent permeability and wave dispersion in tight cracked rocks: Experimental validation of simple effective medium models. J. Geophys. Res. Sol. Ea. 2017, 122, 6180-6201. [CrossRef]

29. Chen, X.; Xu, Z. The ultrasonic P-wave velocity-stress relationship of rocks and its application. B. Eng. Geol. Environ. 2017, 76, 661-669. [CrossRef]

30. Zhang, G.; Li, H.; Xia, X.; Li, J. Wave Velocity and Damage Development of Rock. Chin. J. Rock Mech. Eng. 2015, 34, 2270-2277. [CrossRef]

31. Petružálek, M.; Vilhelm, J.; Rudajev, V.; Lokajíček, T.; Svitek, T. Determination of the anisotropy of elastic waves monitored by a sparse sensor network. Int. J. Rock Mech. Min. 2013, 60, 208-216. [CrossRef]

32. Men, J.; Guo, L.; Lan, T.; Wei, R. Influence of cracks in RC slabs on propagation properties of acoustic emission. J. Harbin Inst. Technol. 2020, 52, 88-95. [CrossRef] 
33. Liu, J.; Zhao, L.; Song, S.; Ji, H. Ultrasonic velocity and acoustic emission properties of concrete eroded by sulfate and its damage mechanism. Chin. J. Eng. 2016, 38, 1075-1081. [CrossRef]

34. Mostafapour, A.; Davoodi, S.; Ghareaghaji, M. Investigation of Wave Propagation Behavior of Partially Two-Layered Plates. J. Test. Eval. 2021, 49, 20180178. [CrossRef]

35. Wu, Y.; Perrin, M.; Pastor, M.; Casari, P.; Gong, X. On the determination of acoustic emission wave propagation velocity in composite sandwich structures. Compos. Struct. 2021, 259, 113231. [CrossRef]

36. Wei, P.; Han, X.; Xia, D. Measurement Method for the Velocity of Acoustic Emission Wave in Liquid Nitrogen. IEEE T. Ind. Electron. 2018, 65, 8232-8238. [CrossRef]

37. Wotzka, D.; Koziol, M.; Nagi, L. Measurement of acoustic emission velocity in natural ester. In Proceedings of the 2019 20th International Scientific Conference on Electric Power Engineering (EPE), Kouty nad Desnou, Czech Republic, 15-17 May 2019; IEEE: Kouty nad Desnou, Czech Republic, 2019.

38. Ministry of Transport of China. Technical specifications for construction of highway asphalt pavements. In JTG F40-2004; China Communications Press Co., Ltd.: Beijing, China, 2004; pp. 1-186.

39. Ministry of Transport of China. Standard test methods of bitumen and bituminous mixtures for highway engineering. In JTG E20-2011; China Communications Press Co., Ltd.: Beijing, China, 2011; pp. 1-361. 